\section{El patrimonio cultural inmaterial y la construcción de subjetividades. Abordajes desde la extensión universitaria para la revalorización de la memoria colectiva en el barrio de Ongay, Corrientes}

\author{
Luciana Sudar Klappenbach \\ Iu_sudar@hotmail.com \\ (iD) orcid.org/0000-0003-2994-0816 \\ Laura Arruzazabala \\ lan.arruzazabala@hotmail.com \\ (iD) orcid.org/0000-0003-1125-5693
}

Universidad Nacional de Nordeste, Argentina

RECEPCIÓN: 12/06/20

ACEPTACIÓN FINAL: 03/09/20
Intangible cultural heritage and the construction of subjectivities. Approaches from university extension in the revaluation of collective memory in Ongay Neighborhood, Corrientes

\section{Abstract}

This article proposes to share theoretical assumptions, methodology and results obtained in a project aimed in the contribution for the construction of subjectivities based on a proposal focused on aspects related to intangible cultural heritage, specifically, those configured in the territory of the Ongay neighborhood of the city of Corrientes. The project was developed at the Faculty of Arts, Design and Cultural Sciences, Universidad Nacional del Nordeste, within the framework of a program of the Secretariat for University Policies, (SPU), (2016-2017).

We present both the experience, and reflections and results regarding a sociocultural process, which took place from the link between the University, the Institute of Culture of the Province of Corrientes and the neighborhood community mentioned above. The purpose of the project was to achieve an approximation to the woven relationship between the social plot and the cultural expressions produced and selected by the neighbors as referents of some shared identities.

Keywords: memory; heritage; subjectivity; identity; university extension.
Sujetos y relaciones en extensión universitaria / Intervenciones 다(1)(2)
Patrimônio cultural imaterial e construção de subjetividades. Abordagens da extensão universitária na reavaliação da memória coletiva no Bairro Ongay, Corrientes

\section{Resumo}

Este artigo propõe compartilhar pressupostos teóricos, metodologia e resultados obtidos em um projeto voltado à contribuição para a construção de subjetividades a partir de uma proposta focada em aspectos relacionados ao patrimônio cultural imaterial, especificamente aqueles configurados no território do bairro Ongay da cidade de Corrientes. O projeto foi desenvolvido na Faculdade de Artes, Design e Ciências Culturais, Universidad Nacional del Nordeste, no âmbito de um programa da Secretaria de Políticas Universitárias (SPU), (2016-2017).

Apresentamos a experiência, as reflexões e os resultados referentes a um processo sociocultural que ocorreu a partir do vínculo entre a Universidade, o Instituto de Cultura da Província de Corrientes e a comunidade do bairro mencionado acima. O objetivo do projeto era obter uma aproximação à relação tecida entre a trama social e as expressões culturais produzidas e selecionadas pelos vizinhos como referentes de algumas identidades compartilhadas.

Palavras-chave: memória; herança; subjetividade; identidade; extensão universitária.

Palabras clave: memoria; patrimonio;

subjetividad; identidad; extensión universitaria. 


\section{Introducción}

En este artículo compartimos los presupuestos teóricos, la metodología y los resultados alcanzados de un proyecto cuyo eje fue el aporte realizado en la construcción de subjetividades a partir de una propuesta centrada en aspectos relacionados con el patrimonio cultural inmaterial, puntualmente, aquellos configurados en el territorio del barrio Ongay de la ciudad de Corrientes. ${ }^{1}$ El mismo, denominado: "Proyecto participativo territorial para la (re)construcción de memorias barriales", ${ }^{2}$ fue desarrollado entre los años 2016 y 2017 en la Facultad de Artes, Diseño y Ciencias de la Cultura (FADyCC) de la Universidad Nacional del Nordeste (UNNE) en el marco del programa: "Universidad, Estado y Territorio", de la Secretaría de Políticas Universitaritas (SPU). Asimismo, esta línea de trabajo fue implementada como eje del Programa "Cultura y Ciudadanía Activa", desarrollado por la Facultad, el Instituto de Cultura de la Provincia de Corrientes, y el Instituto de Investigaciones Geo históricas (IIGHI), UNNE, Consejo Nacional De Investigaciones Científicas y Tecnológicas (CONICET). Interesa destacar el trabajo articulado entre distintos ámbitos: un organismo público nacional (la UNNE), un organismo público provincial (el Instituto de Cultura de Corrientes) y la comunidad del barrio. Esta articulación condujo a un proyecto de intervención y participación con foco en los procesos socioculturales a partir del reconocimiento de valores identitarios, muchas veces compartidos, la escucha y la transmisión de vivencias y conocimientos locales. ${ }^{3}$

El propósito del proyecto fue lograr una aproximación a la relación tejida entre el entramado social del barrio Ongay y las expresiones culturales producidas y seleccionadas por los propios vecinos como referentes de algunas identidades compartidas.

Los objetivos planteados fueron:

- Identificar las expresiones tangibles e intangibles del patrimonio del barrio a partir de las voces de los propios vecinos, mediante la generación de espacios y procesos participativos, y con especial interés en los testimonios de los referentes de distintos grupos generacionales del territorio.

- Promover la construcción personal y colectiva de la historia barrial desde una perspectiva abierta, intercultural, atenta a la diversidad.

- Propiciar la reflexión crítica y propositiva por parte de la comunidad con vistas a la identificación del patrimonio barrial.

- Elaborar productos para la sistematización, visibilización y difusión de los patrimonios locales.

Cabe mencionar también que en el contexto barrial este trabajo constituyó una primera experiencia de participación en procesos de identificación, reflexión y construcción de un cono-

1) Una versión preliminar fue presentada en el Congreso Internacional de Patrimonio Inmaterial. Organizado por $\mathrm{CICOP}$ Argentina, OEI (Organización de Estados Iberoamericanos) y la CRESPIAL, Buenos Aires, del 2 al 4 de octubre de 2017. 2) "Cultura para la inclusión, proyecto participativo-territorial para la (re)construcción de memorias barriales", $22^{\circ}$ Convocatoria de Proyectos de Extensión Universitaria "Universidad, Estado y Territorio" de la Secretaría de Políticas Universitarias. Res. No $3408 / 15$ SPU.

3) En este artículo nos centramos en la experiencia de extensión transitada mediante la implementación de procesos participativos, de revitalización y animación sociocultural, considerando que en el Programa mencionado se abordaron diversos estudios y diagnósticos con miras a ampliar la información y conocimientos de las características socioculturales y económicas del barrio. 
cimiento referido a la propia historia barrial que además incluyó otras temáticas y problemáticas que fueron desarrollándose en forma paralela ${ }^{4}$ en distintos proyectos complementarios.

El abordaje se realizó desde una mirada amplia y comprendió cuestiones significativas de la comunidad que se expresan o manifiestan en prácticas socioculturales. Estas manifestaciones se corresponden con los ámbitos definidos como patrimonio cultural inmaterial, tales como las celebraciones religiosas y festejos, los saberes y prácticas tradicionales, las expresiones artísticas y las creencias que replican en el pequeño fragmento territorial.

El supuesto que orientó el proyecto fue la comprensión del sentido patrimonial que asumen las expresiones inmateriales al funcionar como índices de las identidades representadas por los diferentes grupos y familias.

El encuentro reflexivo y la identificación de un espacio simbólico común nos permitieron observar cómo, a partir del reconocimiento de determinadas prácticas y creencias, es posible fortalecer los lazos comunitarios al mismo tiempo que visibilizar los valores culturales del contexto. Este proyecto aportó nuevos conocimientos en torno al patrimonio cultural regional en contextos desfavorables y al ensayo de metodologías para la identificación y registro de los rasgos culturales del territorio, entendiéndose este como "ambiente de vida, de acción y de pensamiento de una comunidad, asociados a procesos de construcción de identidad" (Tizón, 1995 citado por Murilo, 2007, p. 36).

El presente artículo se compone de cuatro apartados. El primero presenta la caracterización del ámbito de intervención. El segundo plantea los puntos de partida, las perspectivas desde las cuales se abordó la intervención desde la mirada extensionista y la propuesta metodológica para el abordaje de la problemática a la que se quiere dar respuesta. Aquí se explicitan los conceptos teóricos que sustentan el trabajo referidos a: el patrimonio cultural inmaterial, la construcción de subjetividades, la cultura popular, la memoria e identidad, como así las estrategias metodológicas. El tercero expone los resultados obtenidos en el proceso transitado: desde la identificación patrimonial y de los rasgos culturales característicos del barrio, hasta los dispositivos y herramientas generadas por el equipo, tanto para el registro de la información y conocimientos producidos, como para su difusión. Finalmente se presentan las conclusiones.

\section{Caracterización del barrio Ongay}

El barrio Ongay se encuentra ubicado en la zona centro-sur de la ciudad de Corrientes. Si bien originalmente el sector correspondía a un área periurbana, la extensión de la ciudad en las últimas décadas reposicionó el sector en un área más central de la ciudad, si consideramos su actual perímetro. Es un área conformada por un conglomerado de asentamientos informales, configurados en distintos barrios: Ongay, Paloma de la Paz, Irupé, Serantes, Las Rosas, Villa Raquel, algunos de los cuales transformaron su estructura urbana a partir de la intervención del Programa de Mejoramiento Barrial (PROMEBA) desde el año 2005. Este Programa tuvo un impacto favorable en lo habitacional y accesibilidad a servicios básicos (agua potable, luz, eléctrica, cloaca). Si bien el sector en el que se trabajó es común 
y tradicionalmente reconocido como Ongay, debemos aclarar que abarca también el área correspondiente al barrio Paloma de la Paz. ${ }^{5}$ Los límites a los que responden ambos sectores obedecen a razones meramente administrativas, no así el territorio sociocultural que los define. La población del sector, en la actualidad suma aproximadamente 5000 habitantes, es decir el $1,5 \%$ del total de habitantes de la capital correntina ${ }^{6}$ (ver Figuras 1 y 2 ).

Prevalece en este espacio una modalidad de ocupación y usos propios de asentamiento no planificado, con sectores construidos programáticamente a partir de proyectos institucionales. Posee indicadores socioeconómicos desfavorables, según datos estadísticos censales. ${ }^{7}$ Entre ellos, altos índices en la medición de Necesidades Básicas Insatisfechas (NBI), ubicados entre los más elevados de la ciudad; gran parte de la Población Económicamente Activa (PEA) tiene trabajos informales y/o empleos inestables además de presentarse situaciones de desocupación, categorías estrechamente ligadas a factores que dificultaron el acceso y sostenimiento en los niveles de educación superior. Esta coyuntura impacta de manera directa en los ingresos de las familias que, por lo general, son numerosas, y en la calidad de vida.

El modo en que se asentó la población actual obedeció a diferentes procesos, entre los cuales es posible mencionar los loteos y ventas de terrenos pertenecientes a la familia Ongay - de donde deriva el nombre del barrio- que se dieron en la década de 1970. La zona constituía un área de quintas particulares hasta que, en el año 1982, un sector fue adquirido por el gobierno municipal con la finalidad de convertirlo en un pulmón verde de la ciudad. Otro de los procesos dio lugar a la radicación espontánea de los vecinos provenientes de otros barrios, hasta el ordenamiento territorial con la titularización de los terrenos y urbanización llevado a cabo por el ya mencionado PROMEBA en 2005.

En el recorrido sociohistórico también es posible resaltar aquellas particularidades de la convivencia vecinal, manifiestas en los espacios compartidos, en primer término, con la asociación de los primeros vínculos a las labores colectivas como respuesta a las necesidades compartidas, complejizado en el tiempo por el aumento cuantitativo de los habitantes, los intereses diferenciados y las dinámicas propias del entorno. Es así que, cuando se hace alusión a las problemáticas sentidas actualmente, es decir, desde la mirada comunitaria, es posible establecer aquellas vinculadas a la violencia, exclusión y consumo de sustancias nocivas, agravadas por la dificultad en el acceso y permanencia a determinados bienes y servicios institucionales como también al imaginario social dominante que erige una percepción ligada a las condiciones desfavorables.

5) El barrio Ongay es reconocido oficialmente en el año 1972 (Ordenanza 578/72), es el más antiguo del sector y, luego de un proceso de poblamiento, dio lugar a los otros barrios. El barrio Paloma de la Paz fue reconocido por Ordenanza 1572/85.

6) Datos obtenidos de: Municipalidad de la Ciudad de Corrientes. DIR. GRAL. DE SIG. http://gis.ciudaddecorrientes. gov.ar/idemcc/\#15.075601023432986/-27.4884/-58.8150

7) Censo Nacional, 2010. INDEC. 
Figura 1: Localización provincia de Corrientes y ciudad Corrientes capital

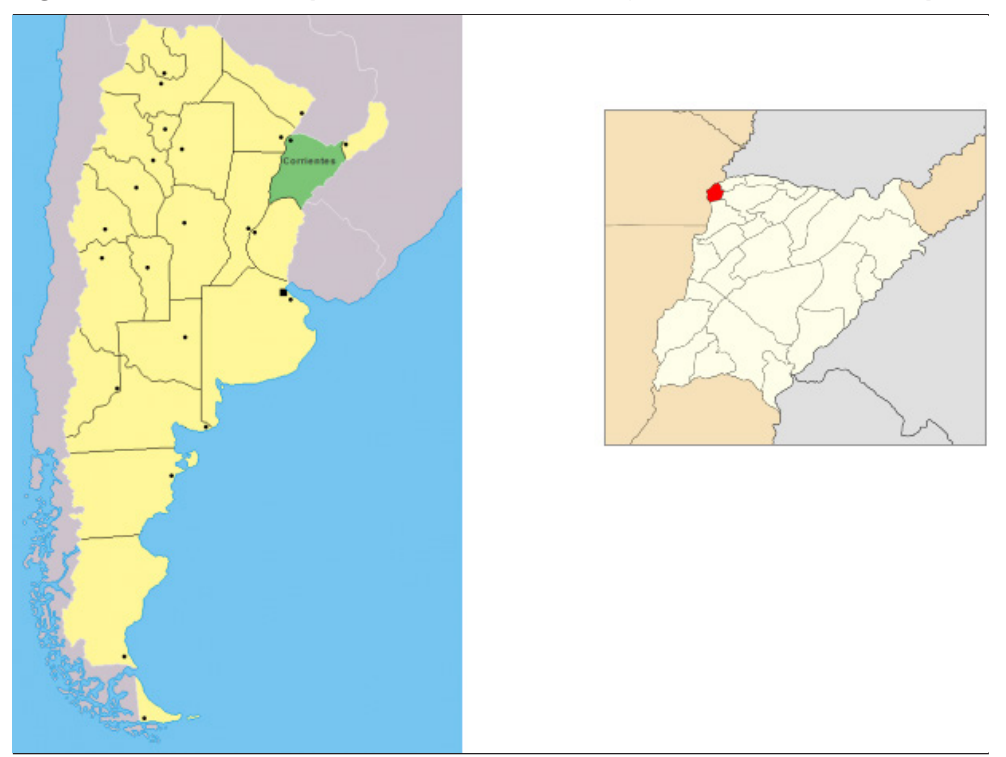

Fuentes: https://www.argentinamapas.net/mapa/mapa-corrientes-localizacion.html\#mapa https://es.wikipedia.org/wiki/Departamento_Capital_(Corrientes)

Figura 2: Ubicación del Área

de Intervención en la ciudad de Corrientes

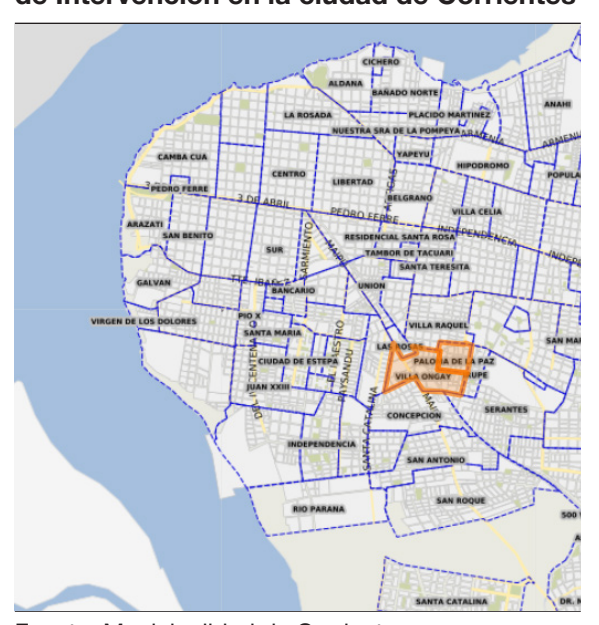

Fuente: Municipalidad de Corrientes.

http://gis.ciudaddecorrientes.gov.ar/idemcc/\#13.

150645479583018/-27.4917/-58.8455

\section{Puntos de partida}

La propuesta fue planteada en el marco de las actividades de extensión y transferencia universitaria, presentada, aprobada y financiada por la Secretaría de Políticas Universitarias del Ministerio de Educación de la Nación (2016-2017). La elaboración de un programa sociocultural fue producto de la construcción de un diagnóstico participativo, de observaciones y relevamientos en el barrio Ongay que llevamos adelante un grupo de profesores de la Universidad, personal del Instituto de Cultura de Corrientes y los vecinos. 
Este proyecto fue congruente con los lineamientos y políticas de extensión establecidas por el Consejo Interuniversitario Nacional (CIN), que la define como:

"espacio de cooperación entre la universidad y los actores de la sociedad de la que es parte. Este ámbito debe contribuir al mejoramiento de la calidad de vida de las personas y está vinculado a la finalidad social de la educación superior: la democratización social, la justicia social, y el derecho a la educación universal, se materializa a través de acciones concretas y con organizaciones sociales, organizaciones gubernamentales y otras instituciones de la comunidad, desde perspectivas preferentemente multi e interdisciplinarias". (Acuerdo Plenario $N^{\circ}$ 811/12)

Esta definición enmarca los principios rectores del proyecto y al mismo tiempo define también una forma de intervención en el territorio y las metodologías de abordaje.

En lo que respecta al ámbito universitario, participaron docentes de distintas cátedras de la FADyCC con diferentes perfiles profesionales: arquitectos, licenciado en Geografía, licenciadas en Asistencia Social, licenciada en Ciencias de la Educación, y alumnos de la carrera de Gestión y Desarrollo Cultural, quienes aportaron una mirada interdisciplinar. Los espacios curriculares desde donde se desarrolló el trabajo fueron: Patrimonio cultural, gestión y promoción, Taller de Práctica II: Gestión de Programas y Proyectos Culturales, Taller de Práctica III: Identificación catalogación de bienes culturales, Ambiente y Territorio, Historia de la Cultura II, junto a personal técnico y docente del Centro de Gestión Ambiental y Ecología (CEGAE), UNNE, organismo dependiente del Rectorado de esta universidad. Por parte del gobierno de la provincia de Corrientes formaron parte: personal del Centro Cultural y de Participación Comunitaria "Esperanza de barrio" (coordinado por el Instituto de Cultura) y personal del Instituto de Cultura, quienes colaboraron en la puesta en marcha del proyecto cumpliendo funciones de logística, convocatoria, aporte de datos del contexto, que facilitaron la ejecución de las actividades. Se sumaron otros actores y organismos cuyos aportes también resultaron fundamentales para cada una de las actividades, entre los que destacamos:

- Directivos y docentes de la Escuela Fe y Alegría, quienes permitieron la realización de los talleres. Los directivos y docentes aportaron el lugar y el equipamiento e hicieron la convocatoria para el desarrollo de los talleres así como trabajos de sensibilización con la población escolar previos a la actividad del proyecto.

- Vecinos entrevistados, quienes pusieron en común datos de sus vivencias personales y colectivas, insumos centrales para la recuperación de la historia barrial.

Las primeras observaciones se realizaron a partir de métodos y técnicas participativas (focus group, talleres de reflexión y producción, actividades y presentaciones artísticas), trabajo de campo, entrevistas, observación in situ, con especial atención en la escucha e interpretación de las reflexiones que los propios vecinos desplegaban acerca de su hábitat.

Uno de los principales problemas detectados mediante estas técnicas de investigación y observación fue el debilitamiento de códigos de convivencia comunes debido al aumento poblacional atribuido, en gran parte, a las migraciones internas y conflictos de intereses de grupos particulares, sumado a otras problemáticas sociales sentidas y evidenciadas por los actores comunitarios (delincuencia, violencia y adicciones), manifestadas expresamente por los mismos en las distintas instancias de encuentro. Sin embargo, este proyecto fue el resul- 
tado de la iniciativa de los propios vecinos, en particular un grupo de mujeres, con quienes recorríamos el barrio semanalmente y que plantearon la posibilidad de trabajar la historia barrial y su patrimonio como estrategia de acercamiento y encuentro de anclajes comunitarios.

\section{Conceptualizaciones y metodología}

La orientación tanto ontológica como epistemológica del proceso se fundó en los siguientes presupuestos: la relación subjetividad y patrimonio; el patrimonio como construcción social; actual dinámica y contextualizada; cultura popular; y patrimonio cultural inmaterial:

- La subjetividad y patrimonio: la subjetividad y la sociedad constituyen dos componentes que, a nuestro entender, forman parte de una complejidad marcada por la interdependencia de ambos; la individualidad y la sociedad no se remiten a compartimentos estanco, sino que se construyen en interacción dialógica sin perder el reconocimiento de sus singularidades. En este sentido, podemos referenciar a Martínez Herrera con esta afirmación: "En la comprensión de la subjetividad se aprehende el entramado social que la define, así mismo, en la interacción societal se devela la dimensión oculta que impregna toda subjetividad" (2005, p. 62). En esta misma línea, profundizamos en la dimensión cultural que, sin dudas, particulariza la connotación colectiva del sujeto en la transmisión de la herencia social y dinámica creativa, las cuales configuran identidades tanto personales como comunitarias.

- El patrimonio como construcción social, actual dinámica y contextualizada: no se trató este de un proyecto desarrollado para "patrimonializar" ni "salvaguardar" expresiones culturales, sino para acompañar un proceso que facilite el redescubrimiento y la reinvención de las subjetividades de los actores comunitarios a partir de la revalorización del patrimonio barrial. Identificar en el marco de la cotidianeidad "referencias culturales como puntos de encuentro" y en un marco de diversidad cultural, y no como lugar de disputa y tensiones. Una concepción del patrimonio que no se ciñe a la idea de que el patrimonio se conforma exclusivamente con los bienes procedentes de culturas tradicionales situadas, ya que los barrios iniciaron su poblamiento paulatino a partir de década del 70, asentándose pobladores provenientes de otros barrios y localidades de la provincia. Por el contrario, se trabajó sobre la idea de patrimonio como expresiones de identidad actual, es decir, como una construcción presente y siempre dinámica (a diferencia de la visión tradicionalista del patrimonio, que lo asume como expresión de un pasado lejano, material y homogéneo). Esta población presenta un perfil de composición heterogénea en cuanto a edades, procedencias (interior de la provincia, Paraguay otros barrios de la ciudad) y actividades, en un contexto urbano, popular, cotidiano.

- Cultura popular: adherimos a la definición de la Recomendación sobre la Salvaguardia de la Cultura Tradicional y Popular:

"Cultura tradicional y popular es el conjunto de creaciones que emanan de una comunidad cultural fundada en la tradición, expresada por un grupo o por individuos y que reconocidamente responden a las expectativas de la comunidad en cuanto expresión de su identidad cultural y social; las normas y los valores se transmiten oralmente, por imitación o de otras maneras. Sus formas comprenden, entre otras, la lengua, la literatura, la música, la danza, los juegos, la mitología, los ritos, las costumbres, la artesanía, la arquitectura y otras artes". (Unesco 1989) 
- El Patrimonio Cultural Inmaterial (PCl): adoptamos la definición expresada en la Convención para la Salvaguarda del Patrimonio Cultural Inmaterial, que entiende al patrimonio cultural inmaterial como:

"los usos, representaciones, expresiones, conocimientos y técnicas - junto con los objetos, artefactos y espacios culturales que le son inherentes- que las comunidades, grupos y en algunos casos los individuos reconozcan como parte integrante de su patrimonio cultural". (Unesco, 2003)

A esta definición que da Unesco agregamos que el PCl queda conformado por todas aquellas expresiones tradicionales producidas y transmitidas en el campo de los colectivos y como prácticas cotidianas. Esta definición consolida un enfoque que reconoce a las personas y grupos como actores principales en la identificación, reconocimiento y gestión del patrimonio cultural, inspira sentimientos de identidad y pertenencia y favorece el diálogo intercultural. El PCl se presenta como excusa para encontrar espacios comunes y reflexionar sobre la propia identidad, interpretar el presente y proyectarse al futuro.

- Memoria: la propuesta de trabajo se orientó a recuperar y revalorizar la memoria histórica del barrio, a partir de una co-construcción del recuerdo colectivo. En este sentido se considera a la memoria como forma de relato del acto de rememoración, sujeto al contexto, al paso del tiempo y a las condiciones colectivas, es decir, a lo que Halbwach (2004) ha llamado "Ios marcos sociales de la memoria". El patrimonio en sus diferentes formas materiales e inmateriales opera, como plantea Candau (2001) como "forma de exteriorización de la memoria", condensando marcas objetivas y simbólicas, historias, mitos creencias e imaginarios que organiza las representaciones identitarias. Es decir, en términos patrimoniales, que la memoria social y cultural se sostiene fundamentalmente en los bienes y procesos que las comunidades, sociedades producen, se remite a ellos para recordar, y se convierten así en referentes de identidad (Sudar Klappenbach, 2019).

- Identidad: esta acepción se plantea como una identidad personal comprendida como "el conjunto de elementos, rasgos y circunstancias que distinguen una persona de otra" (Colombres, 2011, p. 124) y otra vinculada a la esfera social donde la identidad se remite a rasgos de una sociedad, comunidad o grupo que permite distinguirla de otros y a los individuos reconocerse o ser reconocidos por él. Olmos sostiene que la identidad "es la apropiación distintiva de ciertos repertorios culturales que se encuentran en el seno de las sociedades" (2008, p. 37).

A partir de estas nociones se diseñó una estrategia metodológica participativa, tomando también como referencia los aportes de: la promoción cultural, la cual aborda la cuestión cultural como herramienta de transformación social desde los agentes internos (Moras Puig, 2004, Colombres, 2011; Ander Egg, 2010), la animación y revitalización sociocultural ${ }^{8}$ orientadas a investigar, conocer e intervenir colectivamente en torno a los componentes popu-

8) Se retomaron a las experiencias llevadas adelante en Ecuador y Nicaragua, tomando como referencia los manuales editados que sistematizan los aportes metodológicos y didácticos en ambos casos: Manual de Revitalización Cultural Comunitario. Ecuador: COMUNIDEC. Torres, V. H. (1994) y Manual de Revitalización del Patrimonio Cultural Costa Caribe Nicaragua: Herramientas cultura y desarrollo II, Unesco, 2012. 
lares de la configuración identitaria, con implicancias en la valorización comunitaria y de la sociedad en general (Torres, 1994). Entendiendo que estas estrategias pugnan por el trabajo comunitario y la formación de grupos de base que, sustentados en la propia realidad y cultura, y con sus propios recursos y los que sean capaces de generar, se constituyen en los protagonistas de la acción. La estrategia participativa permite visibilizar el conjunto de actores que intervienen en la construcción de las memorias barriales y entender a las expresiones patrimoniales en las propias claves del sujeto social, acorde a la comprensión del patrimonio que asumimos en este proyecto "como construcción social" (Prats, 1997), desde la legitimación de los recuerdos o los procesos de activación de algunos referentes simbólicos de identidad barrial. En este sentido, la participación se remite al proceso de reconstrucción de la memoria colectiva centralizado en el protagonismo de los actores comunitarios, quienes desde sus perspectivas describieron e intercambiaron saberes y experiencias ligados a los aspectos sociohistóricos vivenciados y/o transmitidos.

"La participación siempre es para algo y por algo, resultados de necesidades comunes a todos los miembros de un grupo, organización o comunidad de significados compartidos, que dan sentido a su actividad. Participar es una necesidad para el individuo y a la vez un proceso de comunicación que implica intersubjetividades y presupone representaciones comunes en cada grupo social". (Moras Puig, 2004, p. 105)

La participación promueve el desarrollo de trabajo de campo/territorial, lo cual permite construir lazos de confianza entre la comunidad y los agentes de gestión, conformándose como una plataforma para fortalecer las redes del entramado comunitario y la participación ciudadana. La metodología participativa se articuló con técnicas de revisión bibliográfica y documental, análisis de antecedentes y elaboración de diagnóstico cualitativo. Para la recopilación de historias orales e individuales se realizaron entrevistas a los referentes que se distinguen como los "pobladores más antiguos" del barrio y contactos informales con los vecinos en forma personal. Entre las actividades participativas comunitarias se hicieron charlas y talleres con grupos de discusión, y se implementaron técnicas de construcción de conocimiento y sistematización como pictogramas, línea del tiempo, cuadros comparativos, etc. Asimismo, se reorganizaron instancias de autodiagnóstico comunitario, entrevistas, actividades colectivas en una de las escuelas del barrio, Escuela Fe y Alegría y en el Centro de Participación Comunitaria Esperanza del Barrio. Estas instituciones resultan representativas en el contexto barrial al ser reconocidas por los vecinos como los organismos formales con mayor proximidad a las problemáticas y vivencias del sector. Las actividades se desarrollaron en talleres, grupos de discusión, producción de conocimiento creativo (elaboración de gráficos, dibujos y narrativas ilustradas). Las convocatorias a los talleres y a todas las actividades fueron abiertas para la comunidad. Se contó con la participación de líderes territoriales y comunales, docentes de la universidad, agentes culturales provinciales que manifestaron su interés por el proyecto y por el sector urbano, particularmente, y también con aquellos con posibilidades de aportar a los objetivos planteados. Se destacó desde la iniciativa y en todo el proceso la participación de las mujeres, que en el marco del programa general ya comienzan a constituir un colectivo organizado.

Se efectuaron registros audiovisuales y una sistematización de la información obtenida por medio de documentación y fotografías, volcado todo ello en un Sistema de Información 
y Georreferenciación (SIG), en el cual se registraron los espacios reconocidos por los vecinos como referencias físicas del lugar pero desde sus connotaciones simbólicas.

Por su parte, el trabajo territorial posibilitó la construcción de experiencias cotidianas de diálogo (escucha e intercambio) y abrió espacios para conocer y relevar de forma directa las problemáticas del barrio con referencia a sus modos de apropiación cultural y simbólica. La idea central fue "dar la palabra a los protagonistas y constructores de la historia local", fortalecer la identidad y dar herramientas para la interpretación del presente y su proyección futura.

Las actividades de desarrollo territorial se diseñaron en función de tres ejes orientadores definidos por los objetivos y resultados esperados, lo que su vez demandó la elaboración de diferentes estrategias de abordaje:

1. Memoria viva y patrimonio para el fortalecimiento subjetivo de vínculos sociales.

2. Identificación, valoración y difusión de los patrimonios barriales.

3. Mapeo y georreferenciación de las expresiones patrimoniales y culturales en el barrio.

En tanto, la identificación de los rasgos patrimoniales por parte de la comunidad sentó las bases para la elaboración de un inventario como instrumento sistemático de registro de estas expresiones.

En la identificación de momentos o instancias del proceso de trabajo, es posible mencionar:

- Autodiagnóstico de la comunidad.

- Presentación de resultados parciales con exposición de imágenes e ideas.

- Presentación, consenso y acuerdo en los resultados obtenidos para una publicación.

- Redacción de una publicación (libro) en la que se registraron y sistematizaron los resultados desde un perfil coloquial, pensada en la devolución y difusión en el contexto barrial y editada por la FADyCC y el Instituto de Cultura de la Provincia de Corrientes, con el financiamiento de SPU obtenido del proyecto mencionado.

- Devolución de los resultados: entrega de la publicación a cada uno de los vecinos que participaron, a la Biblioteca Norberto Lischinsky, del Centro Comunitario Esperanza del Barrio, y a la Escuela Fe y Alegría.

\section{Resultados: el patrimonio cultural inmaterial del barrio Ongay}

El trabajo transitado permitió identificar manifestaciones patrimoniales inmateriales en el área de intervención, las cuales se componen de elementos sobresalientes y determinantes en la identidad personal y comunitaria:

\section{Celebraciones barriales y capillas familiares}

Se trata de un conjunto de manifestaciones heterogéneas, diversas, que incluyen: fiestas populares, religiosas, cívicas, representaciones y ritos asociados a determinadas fechas, preparativos y confección de vestimentas y accesorios para rituales y celebraciones, ornamentación de lugares significativos, preparación de bebidas y comidas, músicas, cantos, danzas, juegos y destrezas.

La religiosidad sacro-profana constituye uno de los tópicos fundamentales de las creencias de la comunidad y de la identidad barrial. Las advocaciones corresponden a la Virgen María, particularmente a la Virgen de Itatí, y las devociones a los "santos milagrosos", ya 
sea de aquellos reconocidos oficialmente por la Iglesia Católica o bien "santos populares": Santa Catalina, Santa Librada, San Expedito, el Gaucho Gil, San la Muerte.

Estas manifestaciones se trasladan a espacios sagrados conformados por altares o capillas ubicados en lugares públicos, semipúblicos y domésticos acompañados de elementos ornamentales simbólicos propios de cada culto y distinguidos, sobre todo, por el color: celeste y blanco para la Virgen, rojo para el Gaucho Gil, y negro para San la Muerte. A ellos se suman los "seres celestiales" que intervienen en la sanación de afecciones. Esta práctica se complementa con la administración de hierbas naturales y curación en la que intermedian las denominadas "médicas", las sanadoras.

Las capillas, construidas por los vecinos en sus terrenos particulares, constituyen referencias significativas en el barrio. Son claramente identificables y comportan una dimensión simbólica colectiva para ellos, desde la fe en lo cotidiano Las familias organizan celebraciones y fiestas populares en torno a estas capillas en distintos momentos del año. De este modo interviene la dimensión inmaterial en la valoración de los lugares, en estrecha relación con las celebraciones o convites, denominación que reciben los actos festivos ofrecidos por los vecinos del barrio a "los santos" en sus domicilios particulares en agradecimiento o muestra de devoción, y que generalmente consisten en la organización de alguna comida comunitaria (asado, guiso o chocolatada) acompañada de música y baile.

Siguiendo a Seman (2015), podemos distinguir al menos dos grupos de prácticas, pero no diríamos dos grupos sociales que se afilian a una u otra, sino que asumen ambas como parte de sus creencias, en una suerte de sincretismo que les permite una apropiación más personal a la fe. Por un lado, en las devociones sacro-profanas se distingue a los creyentes cuya sensibilidad implica una elaboración, una toma de distancia crítica respecto de las instituciones religiosas y de la categoría religión en sí misma. Por otro lado, las prácticas relacionadas con el culto institucionalizado comprenden a los creyentes que registran en su apropiación de la religión las mayores improntas de las estrategias institucionales de las denominaciones religiosas. Esta práctica también se asocia a los diferentes grupos etáreos: mientras los mayores adhieren a la fe "institucionalizada", la generación más joven lo hace desde su "sensibilidad", que articula la inmediatez de lo sagrado y su vivencia subjetivante. Es distintiva en el contexto la laicidad, que gana terreno en el ámbito urbano moderno, la persistencia y necesidad de consolidar la sacralización de la fe que resalta como un elemento central en la configuración cultural local, enmarcada por la heterogeneidad de sus relaciones (Grimson, 2011, p. 172). Dado su carácter de institución religiosa católica, la Escuela Fe y Alegría ha venido concentrando algunas de las actividades conmemorativas religiosas, tales como el día de la Virgen de Itatí, la Semana Santa, la Navidad, las fiestas patronales. Estas se complementan con los festejos que se realizan por iniciativa individual en las casas de diferentes vecinos devotos pero que son compartidos por los otros vecinos del barrio.

"Antes se hacían reuniones en la Escuela Fe y Alegría, se [sic] reuníamos seguido cuando estaba la presidenta esta... Mónica Díaz. Pero después falleció ella y medio se achicó la fiesta. El otro que suele hacer fiesta es en la casa de Mártires también". (Entrevista a vecino 1, 22 de noviembre de 2016)

Asimismo, la escuela es el centro de las actividades en las fiestas cívicas o patrias y otras relacionadas con temáticas culturales, por lo que se constituye en una institución y espacio 
que concita la reunión de la comunidad del barrio. Y a las celebraciones patronales religiosas se suman las festividades patrias "oficiales", que también encuentran su lugar de representación allí (Sudar Klappenbach, 2018).

A partir de los talleres realizados y las entrevistas se construyó un calendario anual de celebraciones y festividades que reflejó y confirmó la vigencia de la religiosidad popular en las devociones presentadas, las cuales, en su mayoría, pertenecen al santoral católico y otras forman parte de los llamados santos populares.

\section{Saberes y sabores populares}

En el marco de las prácticas y saberes están la gastronomía y la "medicina popular", entendida como el conocimiento ancestral de la naturaleza, específicamente en el uso de la flora y productos animales destinados a la curación física o espiritual. Representan un "capital cultural" con el cual se sienten identificados y se reconocen como expresiones de una identidad comunitaria. Si bien no podemos advertir en estos saberes y técnicas procesos ancestrales que involucren la producción de materia prima, sí es posible distinguir la transmisión de conocimiento y de una tradición culinaria y su relación con prácticas compartidas en ocasión comunitaria para su preparación. La gastronomía típica se despliega en el contexto de las "celebraciones" comunitarias o familiares. Estas recetas incorporan recursos/productos del medio: mandioca, maíz, carne seca, mamón, y en algunos casos continúan recetas tradicionales guaraníes: mbaipy (con harina blanca), sopa paraguaya, mbeyu, chipa cuerito, torta parilla, dulce de mamón, entre otras a las que se suman preparaciones criollas: arroz con pollo, achuras, asados, mazamorra, bizcochuelo, arroz con leche. Para ilustrar este eje se exponen a continuación algunas recetas de las vecinas:

- Asado a la estaca: "Se prende lindo fuego a leña, va la manta de carne sobre la madera donde va tendida la tapa, arrimada hacia el fuego para que se cocine a fuego lento, primero bien prendida la leña y después va a fuego lento". (Entrevista a vecina 2, 6 de marzo de 2017)

- Sopa paraguaya: "Se pone un kilo de harina de maíz, te salen dos tortas depende del molde que uses, se pone cebolla, preparo primero la mezcla que es la harina de maíz, lo preparás como para hacer una tortilla, le ponés la cebolla, doro la cebolla, algunos lo hacen con cebolla cruda, cada cual hace a su gusto, a su manera, yo doro la cebolla, una cierta cantidad según la cantidad que quieras hacer, yo pongo dos cebollas grandes, huevos más o menos cuatro o cinco huevos, porque los huevos son muy débiles, prácticamente a veces se necesita seis huevos. Si es huevo casero con cuatro ya es suficiente, lo baten bien, le ponés pimiento a gusto y lo ponés al horno. Mi sopa paraguaya, como a mí me gusta, con morrón, la hago con morrón, con orégano y sale saborizada, porque está la otra que es la criolla, la bien tradicional solo lleva cebolla y huevo, nada más". (Entrevista vecina 3, 6 de marzo de 2017)

- Dulce de mamón: "Por cada kilo de mamón verde hay que agregar 700 gramos de azúcar y 1 litro de agua e ir poniendo el agua a medida que va hirviendo. Poner a fuego lento tres horas aproximadamente hasta que el mamón adquiera un color marrón y el jugo se espese a manera de almíbar". (Entrevista vecina 4, 6 de marzo de 2017) 


\section{Medicina popular y uso de hierbas autóctonas}

Dentro de los saberes populares que persisten en la comunidad y se transmiten de generación en generación encontramos el uso de las medicinas naturales para el tratamiento y la cura de algunas enfermedades.

En el plano de los saberes compartidos, en cuanto a la cura de las afecciones, las vecinas resaltaron sus conocimientos transmitidos por herencia familiar muy ligados a las raíces guaraníticas, por lo tanto, más allá del contexto local, los mismos pueden extenderse a la región cultural del Nordeste Argentino, que abarca las provincias de Corrientes, Chaco, Formosa, Misiones, y también a la República del Paraguay.

- Para el malestar de estómago: las hierbas sugeridas son maría negra o maría la negra, cedrón, menta peperina.

- Para el empacho: paico, yerba lucero.

- Para el riñón, la llamada cola de caballo.

- Otras hierbas mencionadas fueron: ajenjo, ambay y llantén.

Las distintas hierbas medicinales no solo pueden ser utilizadas en forma de infusiones (té o mate) sino también en preparaciones como ungüento destinadas a las afecciones del cuerpo u otras externas con la finalidad de "limpiar el ambiente" y atraer la armonía al lugar.

\section{Lenguajes artísticos (música)}

La identificación con la música regional y propia del lugar es un elemento que, al mismo tiempo que separa a distintas generaciones, las reúne en un momento de sociabilización. El chamamé, la cumbia y otros ritmos musicales contemporáneos no cesan de sonar en los corredores del barrio, y tanto adultos como niños los reconocen como propios.

En cuanto a la música chamamecera, están presentes las figuras clásicas o más reconocidas, como el inconfundible sonido del gran artista Tránsito Cocomarola y también Antonio Tarragó Ros, pioneros del chamamé en sus distintos estilos. Entre otros conjuntos correspondientes a la denominada "renovación chamamecera", se destacan los "Hijos de los Barrios", "Los Alonsitos", "Tallarín Ramírez" y "La Pilarcita".

Entre los artistas del barrio se destacan "Los Guapos del Chamamé", conjunto que tiene dos años de conformado y cuyo circuito artístico refiere mayormente a celebraciones populares.

Con referencia a la cumbia, se prefieren algunos grupos musicales que dinamizan el fanatismo de la gente, tal es el caso de "Yiyo y los Chicos 10" y "Eclip c" u otros más afines a la población adulta, como "Los Chaques", "Cirano", "Los Inocentes" y "Santa Cecilia".

\section{Tejiendo nuestra historia}

Apelar a las memorias individuales y ponerlas en diálogo en contexto comunitario a través de diferentes estrategias didácticas y de animación posibilitó construir una urdimbre de hechos, anécdotas, personajes y lugares que se plasman en "una historia común" pero hasta ese entonces desdibujada y otras veces invisibilizada en la memoria colectiva e individual. Algunas informaciones que circulaban como cabos sueltos en el barrio daban cuenta de algún mítico proceso fundacional, y de manera interrumpida y desarticulada aludían a una cierta historicidad sin mucha precisión de la distancia temporal. A partir de las actividades 
y la búsqueda concreta de pequeños resultados por medio de los recuerdos de los propios vecinos y los relatos transmitidos generalmente en el seno familiar, se logró reconstruir una versión de la historia barrial, en la que resaltamos algunos puntos clave que fueron los que se trabajaron en las distintas instancias. El origen del barrio, que pendula entre la transmisión de una historia formal, aquella devenida del loteo de los terrenos de la familia Ongay y de los procesos jurídicos administrativos, de ordenación territorial, y la versión de un poblamiento espontáneo, arraigado en la experiencia vital de los primeros pobladores, que aún viven en el sector. Recuerdos que aluden a hazañas pioneras, surgidas en cierta forma como rupturas de la "legalidad": usurpación de tierras, ejercicio de actividades productivas no permitidas en el ámbito urbano; chancherías; uso del sitio como escondite ante la huida por conflictos sentimentales, entre otros. Asimismo, el paisaje primigenio y sus transformaciones pudieron visibilizarse y recuperar un imaginario del lugar no solo a través de la oralidad sino también de algunas fotografías conservadas por los vecinos. Memorias sobre sus actividades productivas: las chancherías, el acarreo, la venta de tierra negra y de escombros. Los modos de producción de la vivienda y sus trasformaciones desde la tipología de rancho (tipo precario de vivienda con materiales perecederos tales como madera, paja, caña, chapas de cartón), la profusión de casas de material, algunas edificadas por los vecinos (que se distribuyen en sectores específicos dentro del barrio, próximas al terreno del ferrocarril y de la terminal de ómnibus) y otras como parte de los planes de mejoramiento barrial mencionados.

También se rescataron mojones significativos en el barrio en términos patrimoniales asociados a la cultura material, que no profundizamos en este artículo pero sí podemos mencionarlos: la presencia del Ferrocarril Urquiza en un primer momento, sobre la que surgieron testimonios de vida, anécdotas, y se convocó a exempleados ferroviarios que aportaron sus vivencias e historias; ${ }^{9}$ el tanque de agua del complejo ferroviario donde los vecinos se abastecían, como una referencia crucial en el desarrollo comunitario, cuando aún no se contaba con servicio de tendido de red de agua potable - ya que luego, en el lugar que ocupaba la estación de la actual Terminal de Ómnibus se construyó, en los años 70, la primera canilla pública一; en los '80 las instituciones públicas, y de educación, como la Escuela Fé y Alegría, en 1998, de salud, religión; las viviendas de algunos referentes barriales; las capillas domésticas, la "canchita", entre otros. Expresiones materiales culturales que surgieron de este proceso como manifestaciones que dan cuenta de una identidad barrial compartida junto a acontecimientos que se volcaron en una línea de tiempo, en una cronología que los vecinos disponen para seguir alimentándola.

\section{Conclusiones}

El patrimonio cultural inmaterial, lejos de ser una abstracción imperceptible, influye de manera determinante no solo en la construcción de las subjetividades sino también en lo que respecta a la esfera colectiva. Puede identificarse como un componente capaz de tener la función de nexo entre ambas dimensione puesto que, como mencionamos, tiene un rol fundamental en la constitución identitaria en sus múltiples niveles: personal, comunitario, y a la 
vez local, regional, nacional. Estas manifestaciones resultan de suma importancia no solo en la reflexión acerca de las diferentes modalidades, estrategias y oportunidades para conservarlas, sino también en la trasmisión y difusión de generación en generación, que al mismo tiempo aporta y/o enriquece la cuestión subjetiva.

Reconstruir y recuperar las memorias del barrio a través de los relatos de los vecinos y del trabajo compartido en los talleres permitió, en primer lugar, la identificación de cada sujeto en particular y de la comunidad barrial con su propio espacio y la revalorización de sus expresiones culturales en tanto patrimonio cultural. A través de la salvaguarda y revitalización cultural se promociona la participación personal y colectiva, y en este sentido esta experiencia aportó a la creación de espacios de reflexión comunitaria, facilitando a la sociedad barrial apropiarse de los procesos de concientización que surgen de su propia historicidad cultural. Desde este lugar de participación, mediante estrategias de animación sociocultural y de revitalización cultural, cada una de las vecinas y los vecinos participan desde su propio saber y sobre la base de las vivencias personales significativas, aquella memoria compartida emergente de las prácticas culturales y los lugares simbólicos que consolidan sus relaciones de convivencia.

La experiencia transitada logró generar un espacio de participación y socialización además de transformar la manera de mirar y mirarse. El empoderamiento personal a partir de la propia palabra, el protagonismo de la comunidad en la construcción de la historia del barrio y el fortalecimiento de vínculos comunitarios, son algunos indicadores que lo demuestran.

En este contexto, el trabajo realizado sobre la reconstrucción y la co-construcción de las memorias del barrio y de sus patrimonios simbólicos, operó como un dispositivo válido para el restablecimiento de lazos de convivencia y diálogo, como camino de reflexión en la reconstrucción de una alternativa de autoidentificación asociada a valores positivos, alejados de las estigmatizaciones negativas sobre el barrio. Es decir, el reconocimiento, en un contexto de cotidianidad y en un ámbito participativo diverso, en el que estuvieron presentes vecinos, a pesar de sus diferencias y profundas tensiones, de rasgos identitarios muchas veces compartidos, como también la generación de diálogo comunitario con la atención puesta en los significados y valores de sus propias historias. Ello permitió generar también actitudes de escucha y comprender que la convivencia refiere a aspectos que trascienden los puntos de conflicto como únicos anclajes de las relaciones vecinales (como se habían manifestado en los primeros encuentros). $Y$ a este respecto, el ejercicio de mirarse a sí mismos y a los "otros" arrojó la luz necesaria para identificar en la comunidad expresiones valiosas en el ser y en el hacer cultural y social, no solo a escala barrial sino como parte de rasgos compartidos a nivel regional. En las distintas instancias de abordaje: talleres escolares, talleres en el centro comunitario y entrevistas, los vecinos del barrio Ongay recontruyeron una versión de la historia local inmediata e identificaron algunas expresiones identitarias compartidas.

Podemos sintetizar estos resultados en:

- Construcción de la historia del barrio a partir de los relatos personales significativos y de los momentos históricos y lugares de socialización del barrio: las experiencias de vida, la llegada de las primeras familias, el poblamiento, las migraciones, el paisaje original y sus sucesivas modificaciones, los logros comunitarios. ${ }^{10}$ 
- Publicación de un material bibliográfico en soporte físico que visualiza, por un lado, el protagonismo de los sujetos a través de la identificación personal en la coautoría del libro y los créditos en las producciones anexas e imágenes facilitadas. Por el otro, mediante los resultados del proceso de reconstrucción de las memorias barriales, que reflejan tanto los discursos compartidos como las disidencias en los relatos a partir del respeto y/o valoración de la diversidad de opiniones.

- Localización en un mapa del barrio (mapeo): esos acontecimientos y espacios significativos expresados en los relatos, señalados en la cronología histórica elaborada y que operan como referentes en el barrio fueron volcados en un mapa digital en que se registraron otros datos de interés para el desarrollo de la comunidad: calles, calles, pavimentadas, servicios, paradas de autobús, etc. Las referencias están asociadas a los valores sociales y simbólicos del proceso histórico abordado.

- Producción textual y gráfica que permitió recrear el vínculo de los vecinos con su propia historia, además de contribuir a la identificación de la subjetividad en el quehacer cultural.

- Revisión de nuevas visiones y percepciones del sujeto y de la comunidad por medio de la valoración simbólico-cultural del entorno y las historias.

- Identificación, reconocimiento y valoración de la diversidad de expresiones culturales intangibles desde la perspectiva intercultural que facilita el diálogo de los elementos culturales como ejercicio democrático.

- Construcción de espacios de encuentro para la promoción de nuevas formas de empoderamiento, diálogo y convivencia social.

- Enriquecimiento del tejido social mediante la recuperación de su memoria, su patrimonio e historia, la reescritura de su identidad, su proyección al futuro y los lazos comunitarios.

- Identificación de tópicos asociados a la presencia del Ferrocarril en la memoria colectiva, lo que dio lugar a la creación del Centro Comunitario "Estación cultural" en unos de los talleres del ex Ferrocarril Urquiza y el inicio de otro proyecto específico para la recuperación de la memoria de este ferrocarril con la metodología planteada.

- Incorporación desde la práctica de nuevas modalidades de gestión pública desde la Universidad asociada y articulada con otros sectores culturales y educativos.

La experiencia presentada nos lleva a concluir que los procesos de revitalización cultural donde se abordan principalmente dimensiones que pertenecen al campo del patrimonio cultural pueden ser determinantes en el fortalecimiento tanto de los sujetos como de las comunidades a través de la puesta en valor de aspectos subjetivos movilizados por la participación activa al interior del colectivo y su capacidad de creer y crear sus propias posibilidades, rememorando y accionando en pos de las fortalezas para enfrentar los urgentes retos del desarrollo. A ello agregamos que experiencias de este tipo dan cuenta del cumplimiento de funciones propias de la extensión universitaria en cuanto a la promoción de un programa cultural comunitario con participación de distintos sectores y organismos en articulación con la Universidad, el desarrollo de actividades para la difusión de expresiones culturales en sus distintas manifestaciones, y la integración de diferentes claustros y disciplinas al medio sociocultural regional desde su ámbito de formación superior. 


\section{Referencias bibliográficas}

Ander Egg, E. (2010). Léxico del animador sociocultural. Brujas,

Carrillo Raylin (Coord.) (2015). Laboratorio de Prácticas Culturales Sostenibles. Centro de Intercambio y referencia - Iniciativa Comunitaria,

Candau, J. (2001). Identidad y Memoria. Ediciones del sol.

Colombres, A. (2011). Nuevo manual del promotor cultural. T. 1 y 2. Ediciones del Sol.

Flores, M. (2007). La identidad cultural del territorio como base de una estrategia de desarrollo sostenible. Opera, (7), 35-54. https://www.redalyc.org/pdf/675/67500703.pdf

Grimson, A. (2011). Los límites de la cultura. Críticas de las teorías de la identidad. Siglo Veintiuno Editores. Halbwachs, M. (2004). Memoria colectiva y memoria histórica. Traducción de un fragmento del capítulo II de La mémoire collective. PUF, 1968. REIS, (69/95), 209-219. http://ih-vm-cisreis.c.mad.interhost.com/REIS/ PDF/REIS_069_12.pdf

Kush, R. (2000). Sobre indios, porteños y dioses. Obras Completas. Fundación Ross.

Martínez Herrera, M. (2005). Subjetividad y cultura, una mirada freudiana. Reflexiones, 84(2). https://revistas. ucr.ac.cr/index.php/reflexiones/article/view/11422/10771

Moras Puig, P. (2004). Participación Subjetividad e investigación Cualitativa. En Linares Fleies, C.; Moras Puig, P.; Rivero Baxter, Y. La participación, dialogo y debate en el contexto cubano. Centro de Investigaciones y Desarrollo de la Cultura Cubana Juan Marinello.

Prats, L. (1992). El patrimonio como construcción social. Ariel.

Olmos, H. (2008). Gestión cultural y desarrollo: claves del desarrollo. Agencia Española de Cooperación Internacional para el Desarrollo.

Seman, P. (2015). Diferencia y transversalidad en la religiosidad de los sectores populares: mirando con telescopio luego de haber usado el microscopio. Apuntes de investigación de CECYP, (18), 71-107.

Sudar Klappenbach L. (Dir.) (2018). Te cuento mi barrio. Historias de los barrios Ongay y Paloma de la Paz. Facultad de Artes, Diseño y Ciencias de la Cultura. Universidad Nacional del Nordeste.

Sudar Klappenbach L. (2019). Resistencia, del plano a la ciudad. Trazado arquitectura y arte público. EUDENE, UNNE

Torres, V. H. (1994). Manual de Revitalización Cultural Comunitario. COMUNIDEC.

Unesco (2012). Manual de Revitalización del Patrimonio Cultural Costa Caribe Nicaragua. Herramientas cultura y desarrollo II.

Yampey, G. (2003). Mitos y leyendas guaraníes. Manuel Ortiz Guerrero. Patronato de Leprosos del Paraguay.

\section{Documentos}

Unesco (1989). Recomendación sobre la Salvaguardia de la Cultura Tradicional y Popular. París. (2003). Convención para la Salvaguardia del Patrimonio Cultural Inmaterial. París.

Consejo Interuniversitario Nacional. Acuerdo Plenario Nº 811/12. 